\title{
Additional evidence of linkage between Crohn's disease and a putative locus on chromosome 12
}

Huiv'ing Yang, MD, PhD', Jeffery D. Ohmen, PhD', Yuanhong Ma, PhD', Stephan R. Targan, $M D^{3}$, Nathan Fischel-Ghodsian, $M D^{\prime}$, and Jerome I. Rotter, $M D^{1}$

\begin{abstract}
Purpose: The inflammatory bowel diseases (IBD), Crohn's disease (CD), and ulcerative colitis (UC) are chronic intestinal disorder of unknown etiology. Genetic factors play an important role in the pathogenesis of these diseases, but with a complex pattern of inheritance. A number of genome-wide scans have identified several putative susceptibility loci for both $C D$ and $U C$, including a locus on chromosome 12 reported in a set of British families. We aim to evaluate the linkage between CD or UC and this chromosome 12 locus in an independent set of U.S. Caucasian families (36\% being of Ashkenazi Jewish origin). Methods: Microsatellite markers along chromosome 12 spaced at approximately $10 \mathrm{~cm}$ intervals were used to test the putative loci in CD only families (65 sib pairs from 46 families). Regions with positive linkage for CD were then tested in a panel of UC and mixed families (44 sib pairs from 29 families). Two point linkage analysis was performed with SIBPAL. Multipoint linkage analysis was carried out with MAPMAKER/SIBS. Results: We observed evidence of linkage between the region on chromosome 12 and Crohn's disease, because there was a significant excess of allele sharing in CD sib pairs $(\pi=0.62, p=0.0004$ from two-point linkage; and logarithm of the odds score $(L O D)=2.0$ from multipoint linkage). However, we did not observe the same linkage in UC and mixed families $(p=0.48$; not significant [ns]). Conclusion: Our data provided further evidence that the region on chromosome 12 is likely to contain a gene predisposing to CD. Genetics in Medicine, 1999:1(5):194-199.
\end{abstract}

Key words: Linkage, inflammatory bowel disease, chromosome 12, Crohn's disease, genetic study

Chronic inflammatory bowel disease (IBD) presents as two major clinical forms, Crohn's disease (CD) and ulcerative colitis (UC). These are chronic debilitating disorders of the intestine, which occur mostly in young adults with an estimated prevalence of $200-300 / 100,000$ in the United States (for reviews see Calkins and Mendeloff ${ }^{1}$ ). According to estimates of the Crohn's and Colitis Foundation of America, the annual economic cost of IBD was $\$ 1.8$ to 2.6 billion (http://www.ccfa.org).

Ethnic variation of UC and CD, with the Ashkenazi Jewish group having the highest risk, familial aggregation of UC and $C D$, and importantly a much greater concordance rate for monozygotic (MZ) cotwins, as compared with that for dizygotic (DZ) cotwins, all suggest that genetic susceptibility contributes to the development of the disease (for a review see Yang and Rotter ${ }^{2}$ ). Furthermore, the pattern of familial aggre-

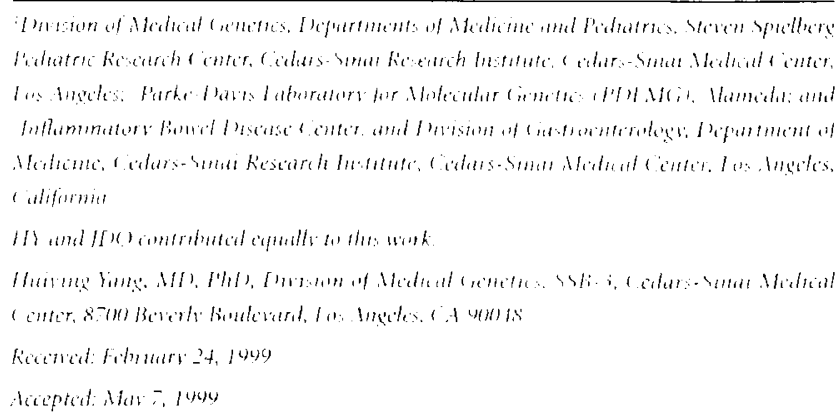

gation is such that $\mathrm{UC}$ and $\mathrm{CD}$ are genetically complex traits. Thus, no single gene can explain the genetic susceptibility to either disorder, and nongenetic factors may play a role in the pathogenesis of the disease as well.

Although UC and CD do occur in the same families with a higher frequency than expected by chance alone, UC and CD have many distinct clinical and subclinical features, as well as distinct genetic determinants. Clinically, inflammation in CD may occur anywhere in the gastrointestinal tract, though it occurs most frequently in the small and large intestines, whereas $\mathrm{UC}$ is characterized by chronic inflammation of the colonic and rectal mucosa. In addition, inflammation in CD is focally involved with skipped normal segments of the intestine, and this inflammation can affect all layers of the bowel wall (transmural in nature); in contrast, in UC, the inflammation is continuous and superficial (only the mucosa is involved). Subclinically, a subset of antineutrophil cytoplasmic antibodies with a perinuclear immunofluorescence binding pattern (pANCAs) is associated with UC but not with CD (for a review see Yang and Rotter ${ }^{3}$ ); whereas antibodies to the cell-wall mannan of Saccharomyces cerevisiae, termed ASCA, are associated with CD, but not UC.,5 Furthermore, the IBD1 locus mapped to chromosome 16 was found to be linked to CD but not to UC in most studies. ${ }^{6-10}$ Lastly, it has been observed that most concordant affected $\mathrm{MZ}$ twins are either both affected with UC or with CD. All these data strongly suggest that $\mathrm{CD}$ and $\mathrm{UC}$ are, to a large extent, 
genetically distinct. Therefore, a genetic linkage study conducted in a uniform disease population, i.e., Crohn's disease alone, should have greater power to identify disease predisposing gene's.

An estimated relative risk to sibs ( $\lambda s$ ) is approximately 30 40 for $C D$ and 10-20 for UC. ${ }^{11,12}$ The larger $\lambda s$ value for CD suggests the potential greater power of identifying disease susceptibility genes using a genome-wide search approach in CD families as compared with UC and other complex diseases, e.g., for Type 1 diabetes, $\lambda s=15^{13}$; for both schizophrenia and Type 2 diabetes, $\lambda s<10$ (see reviews in King et al. ${ }^{14}$ ).

A genome-wide search on British families with multiple affected members with CD or UC identified three putative susceptibility loci on chromosomes 3, 7, and 12. The strongest evidence for linkage of both CD and UC in this study was to a chromosome 12 region spanning $41 \mathrm{~cm}$ (D12S368-D12S95). ${ }^{15}$ This chromosome 12 locus linkage was also observed in a North American Caucasian family panel ${ }^{16}$ and an European cohort, ${ }^{17}$ but was not detected in two other North American Caucasian samples. ${ }^{18,19}$ The aim of our study was to evaluate whether there is evidence of linkage between CD or between UC and a chromosome 12 locus in an independent set of U.S. Caucasian families (36\% being of Ashkenazi Jewish origin). Our results provided further evidence that the region on chromosome 12 is likely to contain a gene predisposing to CD.

\section{METHODS}

\section{Subjects}

Patients diagnosed with CD or UC were ascertained from the IBD programs at Cedars-Sinai Medical Center (CSMC, Los Angeles, CA) or referred by the Crohn's and Colitis Foundation of America, Inc. (New York, NY). The study protocols were approved by the CSMC Human Subject Review Committee. The diagnosis of CD or UC was documented by con- ventional endoscopic, histopathological, and clinical criteria. ${ }^{21}$ Families with two or more siblings affected with CD or UC were selected for the current study. The age ranges at the onset of the diseases for affected sibs were 6-47 years (mean, 21.6) for $\mathrm{CD}$ and $4-46$ years ( mean $=25.3$ ) for UC. Thirty-five percent of CD cases and $26 \%$ of UC cases had an age of onset of 18 years or younger.

A total of 65 CD sib pairs from 46 CD only families (families with no known history of UC) and their parents and unaffected sibs were tested for linkage with microsatellite markers on chromosomes 12 (Table 1A). A panel of UC families and mixed ( with both UC and CD cases) families was used to further test the regions showing significant linkage in CD families (Table 1B). Our sample population is composed of Caucasians from North America, $36 \%$ being of Ashkenazi Jewish origin.

\section{Genotyping}

Genomic DNA was isolated from Epstein-Barr virus (EBV) transformed lymphoblastoid cell lines using QIAamp Tissue columns (Qiagen Inc., Chatsworth, CA) following the manufacturers instructions. All markers are part of the ABI Prism linkage mapping panels (Perkin Elmer/Applied Biosystems Division, Foster City, CA). Genotyping for each of the selected markers was performed by PCR amplification using $75 \mathrm{ng}$ of genomic DNA and $25 \mathrm{ng}$ of each oligonucleotide primer in 15 $\mathrm{ul}$ amplification reactions consisting of $10 \mathrm{mM}$ Tris- $\mathrm{HCl} \mathrm{pH}$ $9.0,50 \mathrm{mM} \mathrm{KCl}, 2.5 \mathrm{mM} \mathrm{MgCl}, 0.1 \%$ Triton X-100, $0.01 \%$ $(\mathrm{w} / \mathrm{v})$ gelatin, $250 \mathrm{mM}$ of each $\mathrm{dNTP}$, and $0.6 \mathrm{U}$ of Ampli-Taq DNA polymerase (Perkin Elmer/Applied Biosystems Division). Amplification conditions consisted of an initial denaturation at $95^{\circ} \mathrm{C}$ for 5 minutes, 10 cycles of denaturation at $94^{\circ} \mathrm{C}$ for 15 seconds, annealing at $55^{\circ} \mathrm{C}$ for 15 seconds, and extension at

Table $1 \mathrm{~A}$

Description of the family panels used for linkage analysis. (.I) only tamilies: Count in cach category by number of affected sibs in a family

\begin{tabular}{ccccccc}
\hline Affected sibs & Families & CD sibs & Unaffected sibs & Parents & Individuals genotyped & Sib pairs \\
\hline 2 & 38 & 76 & 37 & 64 & 177 & 38 \\
3 & 7 & 21 & 6 & 13 & 40 & 21 \\
4 & 1 & 4 & 1 & 0 & 5 & 0 \\
Total & 46 & 101 & 44 & 77 & 222 & 65 \\
\hline
\end{tabular}

Table 1B

Description of the family panels used for linkage analysis. UC and mixcd familics: Count in each category by number of affected sibs in a family

\begin{tabular}{cccccccc}
\hline IBD sibs & Families & CD sibs & UC sibs & Unaffected sibs & Parents & Individuals genotyped & Sib pairs \\
\hline 2 & 25 & 12 & 38 & 33 & 42 & 125 & 25 \\
3 & 3 & 0 & 9 & 9 & 0 & 24 & 9 \\
5 & 1 & 4 & 1 & 0 & 2 & 7 & 10 \\
Total & 29 & 16 & 48 & 42 & 50 & 150 & 44 \\
\hline
\end{tabular}


$72^{\circ} \mathrm{C}$ for 30 seconds, followed by 20 cycles with parameters that were the same as the first 10 cycles, with the exception of a reduction of the denaturation temperature to $89^{\circ} \mathrm{C}$ for the latter. The resulting PCR products were pooled and diluted approximately 20 -fold and denatured before loading on a $36 \mathrm{~cm}$ long, $0.2 \mathrm{mM}$ thick, $4.25 \%$ (6 M Urea) denaturing polyacrylamide gel. Data were collected with an ABI 377 DNA sequencer using ABI PrismTM data Collection software (v. 1.1, PE Applied Biosystems, Foster City, CA). Initial analyses of the gels were accomplished with ABI GeneScan (v. 2.0.2) software. Allele sizes were determined with ABI Genotyper software (v. l.1). Fluorescently labeled oligonucleotide primers were purchased from $\mathrm{ABI}$.

The polymorphic markers analyzed in this study are shown in Table 2. Average distance between two neighboring markers is $11.1 \mathrm{~cm}$.

\section{Statistical analysis}

Two point linkage analysis was performed using the SIBPAL subroutine program (version 2.7 2. $^{21}$ of the Statistical Analysis for Genetic Epidemiology (SAGE) package. ${ }^{22}$ This computerized sib pair analysis program estimates the proportion $(\pi)$ of alleles that the sib pair shares identical-bydescent at that locus. The observed mean proportion of alleles shared by sib-pairs were compared with expected 0.5 by z-test (one-sided). If the linkage between disease and locus exists, an increase of $\pi$ in concordant affected should be observed. Because we were testing specific chromosomal regions reported previously, $p<0.01$ from the two point linkage analysis was considered to be statistically significant as recommended by Lander and Kruglyak. ${ }^{23}$

The MAPMAKER/SIBS program was employed for multipoint linkage analysis to compute maximum likelihood values of the allele sharing proportions $\left(z_{0}, z_{1}, z_{2}\right)$ at each location along the genome and then to compute a maximum LOD score $\mathrm{Z}$ at each location. ${ }^{24}$ Maximum likelihood proportions were estimated under the possible triangle constraint (i.e., $z_{0}+z_{1}+$ $z_{2}=1 ; z_{1}\left(1 / 2 ; z_{1}\left(2 z_{6}\right)\right.$ and using all independent sib-pairs. Genetic distances between the markers were from published Genethon maps. ${ }^{25}$

Allele frequencies for each marker were estimated from parents in the sample. Jewish and non-Jewish families were tested together, as well as separately to examine for potential ethnic heterogeneity. Allele frequencies for Jewish and non-Jewish samples were estimated separately. Because we genotyped parents in most families and genotyped all available unaffected sibs (data from unaffected sibs were used to infer parental genotypes when parents were not studied), the estimated allele frequencies will have no or little effect on the linkage results.

\section{RESULTS}

Two-point linkage analysis of chromosome 12 markers

Because we have available a relatively larger number of $C D$ only families, as compared with UC and mixed families, our initial testing was carried out in the CD only families. As shown in Table 2, we observed significant linkage at the same region as reported in British families on chromosome 12. However, the marker with our highest $p$ value (D12S85) is approximately

Table 2

Polymorphic markers of chromosome 12 and results of two point linkage analysis in CD only families

\begin{tabular}{|c|c|c|c|c|c|c|c|}
\hline \multirow[b]{2}{*}{ Markers } & \multirow[b]{2}{*}{ Distance (cM) } & \multicolumn{2}{|c|}{ All families } & \multicolumn{2}{|c|}{ Jewish families } & \multicolumn{2}{|c|}{ Non-Jewish families } \\
\hline & & $\operatorname{Mean}(\pi)$ & $p$ value & $\operatorname{Mean}(\pi)$ & $p$ value & Mean $(\pi)$ & $p$ value \\
\hline $\mathrm{D} 12 \mathrm{~S} 352$ & 0.0 & 0.55 & 0.093 & 0.51 & 0.42 & 0.57 & 0.063 \\
\hline D12\$99 & 13.8 & 0.54 & 0.20 & 0.52 & 0.38 & 0.55 & 0.20 \\
\hline $\mathrm{D} 12 \mathrm{~S} 336$ & 22.1 & 0.51 & 0.44 & 0.49 & 1.0 & 0.52 & 0.39 \\
\hline D12S364 & 31.9 & 0.58 & 0.044 & 0.61 & 0.068 & 0.56 & 0.16 \\
\hline D $12 S 310$ & 39.0 & 0.56 & 0.056 & 0.62 & 0.039 & 0.52 & 0.31 \\
\hline D12S345 & 56.3 & 0.59 & 0.017 & 0.64 & 0.027 & 0.56 & 0.13 \\
\hline D12S85 & 64.6 & 0.62 & 0.0004 & 0.61 & 0.031 & 0.63 & 0.0027 \\
\hline D12S368 & 68.8 & 0.58 & 0.026 & 0.67 & 0.0048 & 0.53 & 0.33 \\
\hline DI $2 S 83$ & 77.0 & 0.52 & 0.25 & 0.54 & 0.27 & 0.52 & 0.37 \\
\hline DI $2 S 326$ & 90.7 & 0.48 & 1.0 & 0.42 & 1.0 & 0.52 & 0.35 \\
\hline D12S351 & 100.0 & 0.47 & 1.0 & 0.41 & 1.0 & 0.51 & 0.40 \\
\hline D $12 \$ 346$ & 110.0 & 0.49 & 1.0 & 0.43 & 1.0 & 0.52 & 0.37 \\
\hline D12S79 & 130.3 & 0.45 & 1.0 & 0.58 & 0.13 & 0.38 & 1.0 \\
\hline D12S86 & 139.3 & 0.49 & 1.0 & 0.60 & 0.13 & 0.42 & 1.0 \\
\hline $\mathrm{D} 12 \mathrm{~S} 324$ & 152.8 & 0.49 & 1.0 & 0.51 & 0.46 & 0.49 & 1.0 \\
\hline D $12 S 367$ & 166.8 & 0.50 & 0.46 & 0.53 & 0.33 & 0.49 & 1.0 \\
\hline
\end{tabular}


Table 3

Two point linkage results in UC and mixed families

\begin{tabular}{lccc}
\hline \multicolumn{4}{c}{ Chromosome 12 } \\
\hline Markers & Numbers of pairs & Mean $(\pi)$ & $p$ value \\
\hline D12S352 & 40 & 0.49 & 1.0 \\
D12S364 & 38 & 0.48 & 1.0 \\
D12S310 & 43 & 0.48 & 1.0 \\
D12S345 & 39 & 0.52 & 0.33 \\
D12S85 & 39 & 0.48 & 1.0 \\
D12S368 & 40 & 0.44 & 1.0 \\
\hline
\end{tabular}

$12 \mathrm{~cm}$ away from the marker showing the best evidence for linkage in the British sample (D12S83, $p=0.25$ ). The mean allele sharing at marker D12S85 is $0.62(p=0.0004)$, and is $0.59(\mathrm{D} 12 \mathrm{~S} 368, p=0.017)$ and $0.58(\mathrm{D} 12 \mathrm{~S} 345, p=0.026)$ at the two neighboring markers. In this region, the smallest observed $p$ values in Jewish families are at D12S368 $(p=0.0048)$ and in non-Jewish families at D12S85 ( $p=0.0027)$.

Multipoint linkage analysis demonstrated similar results as the two-point analysis (Fig. 1). More specifically, there was a peak of LOD score around marker D12S85 at $64 \mathrm{~cm}$ from the p telomere $(\mathrm{LOD}=2.0)$.

\section{Heterogeneity between CD and UC}

To examine the potential role of the chromosome 12 locus in UC, we used markers that showed excess allele sharing among affected CD sib-pairs (D12S364, D12S310, D12S345, D12S85,
D12S368) to genotype our UC and UC/CD mixed sib pairs from $\mathrm{UC}$ and mixed families. The mean values for alleles shared identical-by-decent were approximately $0.5( \pm 0.02)$ with these markers (see Table 3 ). When the observed mean value of alleles shared identical-by-descent in the CD only sib pairs at D12S85 was compared with that observed in UC and mixed sib pairs, the difference between the two groups reached statistical significance at $p=0.02$ (two-sided test). The chromosome 12 locus therefore appears to contribute specifically to $C D$ in our population.

\section{DISCUSSION}

In our North American Caucasian families, we have provided further evidence to support the findings of Satsangi et al. ${ }^{15}$ regarding the presence of a region on chromosome 12 that appears to encode a gene predisposing to CD. However, the region showing the significant linkage (D12S364 to D12S368) doesn't perfectly overlap with the region reported by Satsangi et al., (D12S368 to D12S95) and the markers with the best evidence for linkage (i.e., the smallest $p$ value) were separated by approximately $12 \mathrm{~cm}$. This difference could not be explained by the informativeness of the markers in the region because the information content for the markers in the two regions was comparable in our sample $(70 \% \sim 80 \%)$. As demonstrated in Figure 1, Jewish and non-Jewish samples appear to have different peaks. The peak in non-Jewish sample appears to overlap the peak observed in British families, whereas the peak in the Jewish samples appears to be approximately $10 \mathrm{~cm}$ proximal. The possibility that there is more than one susceptibility locus on chromosome 12 can not be ruled out. However, additional markers in the region and additional families are needed to delineate the precise region con-

\section{Chromosome 12}

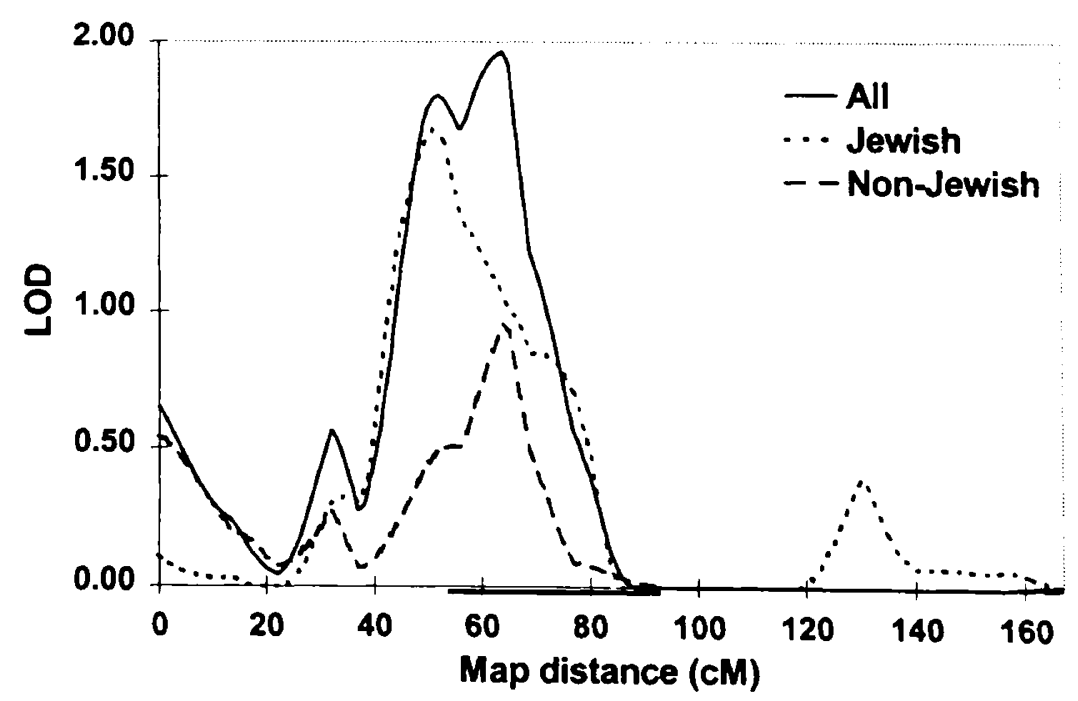

Fig. 1 Maximum LOD score at each location along the chromosome for chromosome 12 for all CD only families as a whole and for Jewish and non-Jewish families separately. The best LOD score (2.0) is located at $64 \mathrm{~cm}$ on chromosome 12. The highlighted areas on the map distance axes are the approximate regions demonstrating positive linkage with IBD in the previously reported British study. ${ }^{15}$ 
taining the $\mathrm{Cl}$ ) susceptibility loci.

Unlike Satsangi et al., ${ }^{15}$ Duerr et al., ${ }^{16}$ and Curran et al., ${ }^{17}$ in which the significant evidence of linkage with the chromosome 12 region was reported in both UC and CD sib pairs together as well as separately, we did not observe any linkage between the region on chromosome 12 with UC in our UC and mixed families. This could be possibly due to the lower power in our UC and mixed families because of the smaller number of families. However, there was no trend toward distortions because the sib pair sharing in these latter families ranged from 0.44 to 0.52 , which was very close to the random expectation of 0.5 . Given other negative reports for linkage in this region, ${ }^{18,14}$ such discrepancy may be evidence for disease heterogeneity or population variation.

It is likely that pooling data and stratifying by ethnic groups will aid in identifying susceptibility genes for any genetically complex diseases. However, until they are available, it is important to report even modest linkage results and review them as a whole, rather than focus on a single $p$ value or LOD score. As of today, both IBD 1 on chromosome 16 and a locus on chromosome 12 have been observed to be linked with either CD only or CD and UC by multiple IBD genetic research groups from Europe and North America. $6,7,4,10,15-17,26,27$ Thus for this complex disease, there is substantial evidence for the involvement of at least two loci.

\section{Acknowledgments}

The authors wish to thank the patients, their families, and referring physicians for their support to our ongoing genetic studies of inflammatory bowel disease. We thank Colleen McElree and Sheila Pressman for their significant contributions to this project by recruiting study subjects (CM) and establishing lymphoblastoid cell lines (SP). This work was supported by the National Institutes of Health Grants DK 46763, DK54967, and the Cedars-Sinai Board of Governors' Chair in Medical Genetics (JIR). Some of the results in this paper were obtained by using the program package SAGE, which is supported by an U.S. Public Health Service Resource Grant (1P41RR03655) from the National Center for Research Resources.

\section{References}

1. Calkin BM, Mendeloff $A J$. The epidemioleng of idiopathic inflammatory berwel disease. In: Kirsner IB, Shorter R(j, cditors. Inflammatory Bowel I)isease. 4th ed Baltimore: Williams \& Wilkins, 1995:31-68.

2. Yang $H$, Rotter II. Cienetic aspects of idiopathic inflammatory bowcl discase. In Kirner IB, Shorter R(; editors. Inflammatory Bowel Dixease. Ath ed. Baltimore: Williams \& Wilkins, 1945;301-331.

3. Yang $\mathrm{H}$, Rotter II. Subclinical markers of human inflammatory bowel disease. Can / Gastroenterol 1945:9:161-167.

4. Lindberg $E$, Magnusson K-E. Tysk (; J Jarnerot $G$. Antibudy $(\lg G, \lg A$, and $\lg M)$ to baker's yeast (Sacharomyces ierevisiue), yeast mannan, gliadin, ovalbumin and betalactoglobulin in monozygotic twins with inflammatory bowel divease. Gut 1992:33:909-913.

5. Sendid B, Quinton IF, Charrier G, Cortot A, Grandbastien B, Poulain D, Colombel JF. Anti-sacharomyces cerevisiae mannan antibodies (ASC (A) in healthy relatives of patients with Crohn's disease. Ciut 1947;41(Suppl 3):A177.

6. Hugot IP, Laurent-Puig P, Gower-Rousseau C. Otson IM, Lee IC, Beaugerie L, Naom I, Dupas IL, Van Gossum A. Orholm M, Bonati-Pillic C. Weissenbach I,
Mathew CG, Lennard-Junes JE, Cortot A, Colombel JF, Thomas G. Mapping of a susceptibility locus for Crohn's disease on chromosome 16 by a genome-wide nonpurametric linkage analysis. Nature 1996;379:821-823.

7. (Ihmen ID, Yang HY, Yamamoto KK, Zhao HY, Ma Y, Bentley LG, Huang Z, Cicrivchr S, Pressman S, McElree C, Targan S, Rotter II, Fischel-Ghodsian N. Susceptibility locus for intlammatory bowel disease on chromosome 16 has a role in Crohn's disease, but not in ulcerative colitis. Hum Mol Genet 1996;5:1679-1683.

8. Cho IH, Fu Y, Kirschner BS, Hanauer SB. Confirmation of a susceptibility locus fur Cruhn's disease on chromosome 16. Inflamm Bowel Dis 1997;3:186-190.

9. Cavanaugh IA, Callen DF, Wilson SR, Stanford PM, Sraml ME, Gorska M, Crawford I. Whitmore SA, Shlegel C, Foote S, Kohonen-Corish M, Pavli P. Analysis of Australian Crohn's disease pedigrees refines the localization for susceptibility to inflammatory bowcl disease on chromosome 16. Ann Hum Genet 1998;62:291-298.

10. Mirza MM, Lee J, Teare D, Hugot JP, Laurent-Puig P, Colombel JF, Hodgson SV, Thomas (;) Easton DF, Lennard-Jones IE, Mathew CG. Evidence of linkage of the inflanmatory bowel disease susceptibility locus on chromosome 16 (IBD1) to ulcerative colitis. Med Genet 1998;35:218-221.

11. Yang H, Rotter II. The genetics of ulcerative colitis and Crohn's disease. In: Kirsner IB, editor. Inflammatory Bowel Disease. 5th ed. Philadelphia: W.B. Saunders, 1994 ;in press.

12. Satsangi J, Jewell DP, Bell JI. The genetics of inflammatory bowel disease. Gut 1997:40:572-574

13. Todd IA. Farrall M. Panning for gold: Genome-wide scanning for linkage in type I diabetes. Hum Mol Genet 1996:5:1443-1448.

14. King RA, Rotter JI, Motulsky AG. The Genetic Basis of Common Diseases. New York: Oxford University Press, 1992.

15. Satsangi J, Parkes M, Louis E, Hashimoto L, Kato N, Welsh $K$, Terwilliger JD, Lathrop (iM, Bell II, Jewell DP. Two stage genome-wide search in inflammatory bowel disease provides evidence for susceptibility loci on chromosomes 3, 7 and 12. Nat Genet 1996;14:199-202.

16. Duerr RH, Barmada MM, Zhang L, Davis S, Preston RA, Chensny LJ, Brown IL. Ehrlich GD, Weeks DE, Aston CE. Linkage and association between inflammatory bowel disease and a locus on chromosome 12. An I Hum Genet 1998:63:95-100.

17. Curran ME, Lau KF, Hampe J. Schreiber S, Bridger S, Macpherson AJ, Cardon LR, Sakul H, Harris TJ, Stokkers P, Van Deventer SI, Mirza M, Raedler A, Kruis W, Meckler U, Theuer D, Herrmann T, Gionchetti P, Lee I, Mathew C, Lennard-Iones J. Genetic analysis of inflammatory bowel disease in a large European cohort supports linkage to chromosomes 12 and 16. Gastroenterology 1998;115:1-7.

18. Brant SR, Fu Y', Fields CT, Baltazar R, Ravenhill G, Pickles MR, Rohal PM, Mann J, Kirschner BS, Jabs EW, Bayless TM, Hanauer SB, Cho JH. American families with Crohn's disease have strong evidence for linkage to chromosome 16 but not chromosome 12. Gastroenterology 1998:115:1056-1061

14. Rioux ID, Daly MI. Green T, Stone V. Lander ES, Hudson T\}, Steinhart AH, Bull S, Cohen Z. Greenberg G, Griffiths A, NicLeod R, Silverberg M. Williams CN, Siminovitch $\mathrm{KA}$. Absence of linkage between inflammatory bowel disease and selected loci on chromosomes 3, 7, 12, and 16. Gastroenterology 1998:115:1062-1065.

20. Podolsky DK. Inflammatory bowel disease. N' Engl / Med 1991:325:928-937.

21. Tran LD), Elston RC, Keats BJB, Wilson AF. Sib-pair linkage program (SIBPAL) user's guide. 3rd ed. Cleveland: Case Western Reserve Lniversity: Part of the SAGE Release 3.0 Documentation, Department of Epidemiology and Biostatistics, Rammelkamp Center for Education and Research, MetroHealth Campus, 1997.

22. SAGE: Statistical Analysis for Cienetic Epidemiology, Release 3.0. Computer program axulable from the Department of Epidemiology and Biostatistics, Rammelkamp Center for Education and Research, MetroHealth Campus. 3rd ed. Cleveland: Case Western Reserve University, 1997.

23. Lander ES, Kruglyak L. Genetic dissection of complex traits: Guidelines for interpreting and reporting linkage results. Nat Genet 1995;11:241-247.

24. Kruglyak L. Lander ES. Complete multipoint sib-pair analysis of qualitative and quantitutive traits. A $m$ I Hum Genet 1995:57:4.39-454

25. Dib C, Fuure S. Fizames C, Samson D, Drouot N, Vignal A, Millasseau P, Marc S, Hazan J. Seboun E, Lathrop M, Gyapay (J. Morissette J, Weissenbach J. A comprehensive genetic map of the human genome based on 5264 microsatellites. Nature 1996:380:152-154

26. Parkes M, Satsangi J, Lathrop GM, Bell JI, lewell DP. Susceptibility loci in inflam matory howel disease. Lancet 1996:348:1588.

27. Cho JH, Nicolae DL, Gold LH, Fields CT, LaBuda MC, Rohal PM, Pickles MR, Qin L, Fu Y, Mann IS, Kirschner BS, Jabs EW, Weber J, Hanauer SB, Bayless TM, Brant SR. Identification of novel susceptibility loci for inflammatory bowel disease on chromosomes 1p, 3q, and 4q: Evidence for epistasis between lp and IBD1. Proc Natl Acad Sci USA 1998;95:7502-7507. 